\title{
Potencialidades e limitações de um trabalho colaborativo sobre frações com estudantes de Pedagogia
}

\author{
Marlene Menegazzi* \\ Andreia Dalcin ${ }^{* *}$
}

\section{Resumo}

O texto apresenta um trabalho de pesquisa que teve como objetivo identificar as concepções de frações que um grupo colaborativo, constituído por estudantes de Pedagogia, apresentam e analisar de que modo a participação nas atividades do grupo contribuiu para o processo de ressignificação de tais concepções. Através de uma abordagem metodológica qualitativa, da triangulação dos dados à luz da teoria sócio-histórica de Vigostki, da educação matemática crítica de Skovsmose e das comunidades de prática de Wenger, foi possível identificar significativas características de um grupo colaborativo em formação. O trabalho do grupo foi capaz de gerar algumas ressignificações das concepções de frações, viabilizando uma diferente opção de formação.

Palavras-chave: Formação dos Profissionais da Educação. Ensino de Matemática. Métodos de Aprendizagem.

\footnotetext{
* Mestre em Ensino de Matemática pela Universidade Federal do Rio Grande do Sul (UFRGS). Professora do Centro Universitário Ritter dos Reis (UNIRITTER).

*** Doutora em Educação pela Universidade Estadual de Campinas (UNICAMP). Professora do Departamento de Ensino e Currículo e do Programa de Pós-Graduação em Educação em Ciências Matemáticas na Universidade Federal do Rio Grande do Sul (UFRGS).
} 


\section{Introdução}

O presente artigo tem por objetivo apresentar os resultados de um trabalho desenvolvido junto ao Programa de Pós-Graduação em Ensino de Matemática da Universidade Federal do Rio Grande do Sul (UFRGS). A pesquisa originou-se a partir de inquietações e questionamentos oriundos das experiências e reflexões das autoras como formadoras de professores, atuando em cursos de Pedagogia e Licenciatura em Matemática. A escolha da temática frações decorreu da ciência de que os alunos, independentemente do nível escolar, apresentam dificuldades na aprendizagem de tal conteúdo matemático. Além disso, identificamos poucos estudos com a temática frações que tomem como objeto de investigação estudantes dos cursos de Pedagogia.

A opção por um estudo na perspectiva dos grupos colaborativos se configura a partir da leitura de diferentes trabalhos com essa abordagem que vem sendo desenvolvidos em várias instituições de ensino superior do Brasil, mas, sobretudo, pelo fato da maioria das pesquisas com grupos colaborativos ter seu foco na formação continuada e na relação entre a prática profissional e a formação do professor, sendo ainda reduzido o número de trabalhos associados à formação inicial do professor dos anos iniciais. Desse modo, entendemos como adequado e necessário o desenvolvimento da presente pesquisa na qual nos envolvemos por dois anos.

A pesquisa foi desenvolvida tomando como problemática central "verificar as possibilidades de um trabalho colaborativo na formação inicial dos professores que ensinam frações", e resultou na dissertação de mestrado profissional defendida em março de 2014 (MENEGAZZI, 2014). Nesse momento, propomo-nos apresentar uma síntese deste trabalho e seus resultados.

Iniciamos apresentando as ideias norteadoras da investigação, bem como os procedimentos metodológicos adotados. Na sequência exploramos os resultados obtidos no sentido de desvelar algumas possibilidades da trajetória descrita. Por fim, expomos os resultados dessa investigação colocando algumas considerações finais acerca do vivido, apresentando algumas possibilidades de desdobramentos, consequências e direcionamentos da pesquisa. 


\section{Os caminhos da pesquisa}

Gatti e Nunes (2009) apresentam em seu trabalho de pesquisa diferentes categorias de agrupamento para as disciplinas que compõem os currículos dos Cursos de Licenciatura em Pedagogia, que são: fundamentos teóricos da educação, conhecimentos relativos aos sistemas educacionais, à formação profissional específica, às modalidades e nível de ensino específico, outros saberes, pesquisa e trabalho de conclusão de curso e atividades complementares. $\mathrm{O}$ interesse do nosso estudo se refere ao grupo de disciplinas que constituem os conhecimentos sobre a formação profissional específica, sendo de forma particular, as disciplinas relacionadas à Matemática.

Dentre os dados apontados pelos autores, consideramos relevante o fato de que $30 \%$ das disciplinas que compõem os currículos dos Cursos de Pedagogia são de formação profissional específica. Destacamos ainda que os conteúdos a serem ensinados pelos professores aos alunos dos anos iniciais do ensino fundamental, da educação infantil e da Educação de Jovens e Adultos (EJA) estão circunscritos às áreas de Alfabetização, Língua Portuguesa, Matemática, História, Geografia, Artes, Ciências e Educação Física.

O estudo dos conteúdos dessas diferentes áreas não está contemplado nas disciplinas dos cursos. Eles apenas são utilizados como ferramentas para o desenvolvimento das diferentes metodologias de ensino. Os conteúdos específicos das diferentes áreas são desenvolvidos sem aprofundamento disciplinar e lógico-conceitual necessários ao futuro professor, que terá de planejar, ministrar e avaliar um ensino baseado nesses conhecimentos. Nessa perspectiva, os autores como Nacarato, Passos e Carvalho (2004) afirmam que um dos grandes desafios para os formadores de professores que ensinam ou ensinarão Matemática - graduandos da Pedagogia - não reside apenas em romper barreiras e bloqueios que estes trazem de sua formação matemática da Escola Básica, mas, principalmente, em provocar a percepção desses fatos, trazendo-os à tona para que possam ser objeto de reflexão, superação e (re)significação.

Vários pesquisadores se dedicam à área de formação de professores que ensinam Matemática, considerando professores de todos os níveis de ensino, desde a Educação Infantil até o Ensino Superior. Buscamos como exemplo o grupo de trabalho sete (GT7), da Sociedade Brasileira de Educação Matemática, constituído oficialmente no final do ano de 2000, e que busca discutir e analisar os saberes profissionais e a formação dos professores que ensinam Matemática. Tal grupo verificou que há muitas questões em aberto. E uma delas, considerada como uma questão central, é o fato de que não se pode 
conceber uma formação inicial ou continuada sem levar em consideração o conteúdo matemático: "Há a necessidade de repensar a formação inicial em relação aos conteúdos conceituais e suas respectivas metodologias" (NACARATO; PAIVA, 2013, p. 14).

O grupo verificou que a ideia de cooperar/colaborar, contar com o interesse e a participação ativa de todos os envolvidos, a cumplicidade entre professores e formadores, e dar espaço para o professor se expressar passou a ser a nova ênfase de muitas pesquisas. Essa valorização do fazer e das necessidades do professor vai ao encontro do conceito de desenvolvimento profissional, que pressupõe o professor como agente de seu próprio conhecimento, partindo dele a necessidade de estar em permanente formação. E, como afirma Nacarato e Paiva (2013), o desenvolvimento de trabalhos voltados a esse tema evidencia a necessidade de trabalhos colaborativos, ressaltando seu potencial no desenvolvimento profissional dos professores.

\section{Grupos colaborativos como comunidades de aprendizagem}

Nosso estudo acerca de grupos colaborativos está alicerçado na teoria de Wenger (2001) sobre comunidades de prática, pois os conceitos seus detalhados e o consequente entrelaçamento dos seus significados possibilitam melhor compreensão e uma análise mais aprofundada dos registros obtidos durante nossa pesquisa.

O autor aborda diferentes conceitos e dimensões partindo do fato de sermos todos seres sociais, do conhecimento ser uma questão de participação na execução de um dado empreendimento, do comprometimento de maneira ativa com o mundo e nosso compromisso com ele como algo significativo. O conceito de comunidade de prática adotado integra as ideias de comunidade, prática, significado e identidade. Todos pertencemos à comunidades de prática durante nossas vidas e, como exemplos simples, temos a própria família e o ambiente de trabalho, sendo as mesmas parte integrante de nosso cotidiano. A teoria sócio-histórica de Vigotski (1984) fundamenta essa ideia ao considerar a mente humana como social e culturalmente construída e, a partir disso, temos uma nova análise do processo de construção do conhecimento.

Conforme Wenger (2001), o modo de viver dos seres humanos está relacionado a realizarmos diferentes tarefas com o objetivo de sobrevivência ou, simplesmente, por prazer. Quando estabelecemos as tarefas e participamos de suas realizações, interagimos com os demais e com o mundo, consequentemente, ajustamos nossas relações com o mundo e com os demais. Em outras palavras, aprendemos. A aprendizagem coletiva resulta numa prática que reflete a busca pelo alcance 
dos objetivos do grupo. E, para isso, essas práticas são o produto de uma comunidade específica, criada com o tempo, mediante um objetivo comum compartilhado. Esses tipos de comunidades são denominados de "comunidades de prática" (WENGER, 2001).

$\mathrm{O}$ autor afirma que viver é um processo constante de negociação de significados. Essa negociação supõe uma distinção entre interpretar e agir, fazer e pensar ou compreender e responder. A negociação de significados transmite a ideia de uma interação contínua, de ganho gradual e de um processo de trocas contínuas. Dessa forma, "a negociação de significado supõe a interação de dois processos constitutivos que denominarei por participação e coisificação" (WENGER, 2001, p. 76).

O termo participação é empregado para descrever a experiência social de viver no mundo do ponto de vista da afiliação em comunidades sociais e da intervenção ativa nos empreendimentos sociais. É um processo que combina fazer, falar, pensar, sentir e pertencer, e desenvolve a possibilidade de um reconhecimento mútuo, ou seja, o desenvolvimento de uma identidade de participação constituída mediante relações de participação.

A coisificação não é um termo comum como participação, mas é muito útil como produtor de significado. De forma geral, o conceito de coisificação de Wenger (2001) representa uma maneira para designar o processo de dar forma a nossa experiência, produzindo objetos que representem a experiência em determinadas coisas. Nossa identidade é obtida através de uma interação entre a participação e a coisificação e, conforme passamos por diferentes formas de participação, criamos trajetórias.

Nas comunidades de prática de Wenger (2001), a associação dos termos comunidade e prática devem ser consideradas como uma unidade relacionada a três dimensões que lhe conferem coerência: compromisso mútuo, empreendimento conjunto e tarefas compartilhadas. O compromisso mútuo constitui-se como a característica da prática que confere coerência a uma comunidade. A afiliação a uma comunidade de prática é uma questão de compromisso mútuo, onde os integrantes participam de ações cujos significados negociam coletivamente. A segunda dimensão é a negociação de uma “empresa conjunta", um empreendimento conjunto. Temos que esse empreendimento conjunto é o que mantém unida uma comunidade de prática. Ela representa o resultado de um processo coletivo de negociação que reflete toda complexidade do compromisso mútuo. Não representa simplesmente uma meta estabelecida, mas cria entre os participantes uma relação de responsabilidade mútua. A terceira dimensão da prática como coerência para a comunidade e seu desenvolvimento são as tarefas compartilhadas, que incluem rotinas, palavras, instrumentos, relatos, gestos, símbolos, maneiras de 
fazer, conceitos ou ações que a comunidade tenha produzido e adotado durante sua existência e passou a fazer parte de sua prática.

A construção da identidade sob o ponto de vista da afiliação às comunidades de prática também é um aspecto importante a ser apresentado. Para compreender os processos de formação de identidade e aprendizagem se faz necessário considerar três modos distintos de afiliação: compromisso, imaginação e alienação.

Uma dada comunidade pode estar constituída pelas três em diversas proporções e pela variedade de combinações entre elas, produzindo comunidades com características distintas. O compromisso é o trabalho de formar comunidades de prática, a imaginação requer a capacidade de distanciar-se e observar nosso compromisso com os olhos dos outros e a alienação consiste na capacidade de coordenar as perspectivas e ações para orientar as energias para um objetivo comum. Em geral, esse trabalho comporta convencer, inspirar, unir, conciliar práticas divergentes, encontrar um terreno comum.

Wenger (2001) afirma que com compromisso, imaginação e alienação combinados de forma eficaz, uma comunidade de prática pode se converter em uma comunidade de aprendizagem. E quanto à aprendizagem, esta não pode ser planejada, pois a mesma pertence ao meio da experiência e da prática, com a negociação de significados e se desenvolve de acordo com os seus próprios caminhos. A aprendizagem tem seu caráter de imprevisibilidade, podendo ocorrer de forma inesperada, enquanto que o ensino está coisificado através de um planejamento. Os dois não estão intrinsecamente unidos, sendo que o ensino é apenas um dos muitos recursos de estruturação utilizados no processo de aprendizagem.

Por sua vez, o trabalho com grupos colaborativos já vem sendo desenvolvido em algumas universidades brasileiras de forma institucional ou independente, onde o principal objetivo está voltado ao desenvolvimento de atividades investigativas que integrem os conhecimentos de pesquisadores das universidades com os conhecimentos produzidos pelos professores da educação básica e licenciados. As pesquisas realizadas são norteadas pela percepção de que o conhecimento profissional dos professores não apenas resulta de uma integração entre teoria e prática, mas também é pessoal e se manifesta, especialmente, pela ação. E o desenvolvimento profissional dos professores pressupõe um envolvimento intencional em um projeto no qual deverão refletir sobre sua prática, individual e coletivamente. A prática pautada numa relação dialógica, em que seus participantes se sentem em igualdade num ambiente de mútua aprendizagem, favorece o processo de formação dos participantes e 
dos pesquisadores.

Fiorentini e Nacarato (2005) apresentam diversos trabalhos comungando a preocupação com a relevância da formação de professores, seja ela inicial ou continuada, como um processo que possa ajudá-los a se tornarem os protagonistas de seu desenvolvimento profissional e do processo educacional. Os autores Fiorentini, Grando e Miskulin (2009), através da apresentação dos resultados de trabalhos voltados às práticas de formação e pesquisa de professores que ensinam matemática, também evidenciam a contribuição do trabalho colaborativo e a importância da teoria social da aprendizagem.

No entanto, a dimensão social extrapola os limites de uma discussão centrada no aprendizado de conteúdos matemáticos escolares e nos provoca a problematizar a natureza dos conhecimentos matemáticos, na relação com as práticas culturais e sociais, o que nos impulsionou para a Educação Matemática Crítica.

\section{A formação de professores e a Educação Matemática Crítica}

A identificação de diferentes questionamentos que, por sua vez, geram novas inquietações nos remete à importância do pensamento crítico na formação de professores. $\mathrm{O}$ ato de olhar ao redor, de procurar os detalhes não tão óbvios, de ler e interpretar através das entrelinhas se faz necessário. As seguintes questões se impõem: por que ser professor? O que representamos e o que reproduzimos na sociedade? O que é matemática? O que é ensinar matemática? Na tentativa de elucidar tais questões nos aproximamos da concepção política e social da Educação Matemática, na qual os trabalhos de Skovsmose (2001) subsidiam a discussão, relacionando a Educação Matemática à Educação Crítica, e, ainda, seu papel no desenvolvimento da democracia.

O trabalho de formação docente necessita oportunizar a todos a visão deles mesmos - docentes - como agentes potencialmente ativos e comprometidos em mudar situações opressivas que os reduzem a meros técnicos encarregados da realização de ideias e projetos alheios a seus interesses profissionais.

A Educação Matemática Crítica (EMC) traz à tona discussões sobre os diversos papéis sociopolíticos que a Educação Matemática pode desempenhar, ajudando a compreender de que modo a matemática pode auxiliar a estratificar, selecionar, determinar e legitimar inclusões e exclusões sociais. Olhar, além avistar o que outros não veem, é a proposta da EMC, que é considerada como uma forma de pensar. 
O desafio de ser professor frente às diferentes demandas é significativo:

Mas, ao mesmo tempo que os professores são desafiados a criar e renovar a sociedade informacional ou do conhecimento, são também convocados pelos educadores críticos a assumir o papel de contrapontos à perspectiva pragmática da sociedade tecnológica atual, amenizando seus efeitos perversos, questionando e problematizando o consumismo e o individualismo, denunciando as injustiças e a desigualdade social. Espera-se, assim, que os professores, como contrapartida, promovam: valores éticos, respeito mútuo e o bem comum; trabalho colaborativo e cooperativo; relações de cuidado com o outro e com o bem-estar social; desenvolvimento social e emocional [...]. (FIORENTINI; NACARATO, 2005, p. 90).

A questão que se coloca é: o que queremos que nossos alunos aprendam? Ou ainda, como devemos ensinar? Qual a relevância do conteúdo a ser desenvolvido? A educação matemática pode efetivamente contribuir com o exercício da democracia?

Nessa perspectiva, o trabalho com os professores também precisa se dar de forma crítica, de maneira que a capacidade de questionamento que se pretende deles possa seguir uma lógica progressiva. É necessário potencializar um trabalho com os professores para que eles descubram as interpretações de como se constitui historicamente seu contexto de atuação e as implicações da dinâmica social sobre ele. Instituir um diálogo capaz de fazer com que o reconhecimento e a análise dos fatores que limitam a ação dos professores sejam perceptíveis a todos. A natureza crítica da Educação Matemática causa uma grande incerteza e o primeiro passo a ser dado é reconhecê-la.

$\mathrm{O}$ desenvolvimento da cidadania crítica implica em diferentes competências ligadas à matemática como: habilidade de lidar com noções matemáticas, habilidade de aplicar tais noções em contextos distintos e, ainda, refletir sobre tais aplicações. Essa última competência é fundamental para o desenvolvimento dos indivíduos, de tal forma que possam ir além das limitações impostas por situações sociopolíticas. Temos que conhecer os riscos estruturais que acompanham o desenvolvimento da sociedade, identificar tanto as forças produtivas como as destrutivas do desenvolvimento tecnológico. Necessitamos entender o que a matemática faz para a sociedade e o que nós, professores, fazemos com ela.

De acordo com essa perspectiva, a criação de novos espaços geradores de questionamentos e suas respectivas análises se faz necessária. Nesse sentido, as comunidades de prática e os grupos colaborativos surgem como uma alternativa para o desenvolvimento de um trabalho de reflexão, discussão, análise e criação na formação de professores. 


\section{O estudo das frações}

Resultados de diversas investigações (SILVA, 1997) têm identificado problemas de compreensão sobre números racionais que não se superam durante a Educação Básica, perpetuando-se no Ensino Médio e ainda no Ensino Superior. Da mesma forma, preocupa-nos o fato de que, inclusive os professores durante o processo de formação ou em exercício profissional, carregam sérias dificuldades relativas a este conceito.Os números racionais e as suas interpretações são abordados em diferentes trabalhos e destacam a ideia de que uma compreensão completa desses números não só requer a compreensão de cada uma de suas concepções como, também, da relação entre cada uma delas.

No que diz respeito à aprendizagem, os alunos podem até apresentar algumas habilidades em manipular os números racionais sem necessariamente ter uma compreensão clara do conceito. Nunes e Bryant (1997, p. 191) argumentam que:

Com as frações as aparências enganam. Às vezes as crianças parecem ter uma compreensão completa das frações e ainda não a têm. Elas usam os termos fracionários certos; falam sobre frações coerentemente, resolvem alguns problemas fracionais; mas diversos aspectos cruciais das frações ainda lhes escapam. De fato, as aparências podem ser tão enganosas que é possível que alguns alunos passem pela escola sem dominar as dificuldades das frações, e sem que ninguém perceba.

A literatura vem apresentando vários tipos de categorização para o número racional (KIEREN, 1981; NUNES, 2003; SILVA, 2006; DAMICO, 2007; TEIXEIRA, 2008). Neste trabalho, consideramos cinco categorias: parte-todo, quociente, operador, medida e coordenada linear. Destacamos que, embora feita a escolha das categorias a serem analisadas em nossa pesquisa, estamos cientes de que, do ponto de vista do ensino, não é possível isolar completamente cada uma delas das demais. Algumas delas têm vinculações naturais que não se podem ignorar e fazem com que, ao se tratar de um determinado aspecto de uma categoria, outras estejam implicitamente presentes.

No Quadro 1 procuramos apresentar de forma objetiva e direta as cinco categorias, também denominadas de significados ou subconstrutos das frações, que elencamos para a nossa pesquisa, acrescidos de exemplos. 
Quadro 1 - Os cinco significados de fração

\begin{tabular}{|c|c|c|}
\hline Significado & Definição & Exemplo \\
\hline Parte-todo & $\begin{array}{l}\text { Partição de um todo em n partes iguais, em } \\
\text { que cada parte pode ser representada por } 1 / \mathrm{n} \text {. } \\
\text { Um procedimento de dupla contagem, das } \\
\text { partes do todo e das partes tomadas. }\end{array}$ & $\begin{array}{l}\text { Uma barra de chocolate foi dividida } \\
\text { entre três partes iguais. Maria comeu } \\
\text { duas partes do chocolate. Que fração } \\
\text { da barra de chocolate representa o que } \\
\text { Maria comeu? }\end{array}$ \\
\hline Quociente & $\begin{array}{l}\text { A fração indica uma divisão e seu resultado. } \\
\text { Nas situações de quociente temos duas } \\
\text { variáveis: o numerador e o denominador. }\end{array}$ & $\begin{array}{l}\text { Duas pizzas foram divididas entre } \\
\text { cinco amigos igualmente. Quanto } \\
\text { cada um vai receber? }\end{array}$ \\
\hline $\begin{array}{l}\text { Operador } \\
\text { multiplicativo }\end{array}$ & $\begin{array}{l}\text { A fração é um valor escalar aplicado a uma } \\
\text { quantidade, ou seja, um multiplicador da } \\
\text { quantidade indicada. }\end{array}$ & $\begin{array}{l}\text { Tenho } 12 \text { balas e de } 3 / 4 \text { destas balas } \\
\text { para Maria. Quantas balas eu dei? }\end{array}$ \\
\hline Medida & $\begin{array}{l}\text { Comparação na qual a fração está } \\
\text { relacionada à pergunta quantas vezes? Neste } \\
\text { caso, uma determinada parte é tomada como } \\
\text { referência para se medir outra. }\end{array}$ & $\begin{array}{l}\text { Tomando-se o segmento } \overline{A B} \text { como } \\
\text { unidade de medida, quanto mede o } \\
\text { segmento } \overline{C D} \text { ? } \\
\text { A_B } \\
\text { Outro caso: Temos } 4 \text { latas de leite } \\
\text { condensado que são suficientes para } \\
\text { fazer dois pudins. Quantos pudins } \\
\text { poderemos fazer com } 10 \text { latas de leite } \\
\text { condensado? }\end{array}$ \\
\hline $\begin{array}{l}\text { Coordenada } \\
\text { linear }\end{array}$ & A fração expressa um número na reta real. & $\begin{array}{l}\text { Localize, aproximadamente, a fração } \\
2 / 5 \text { na reta numerada. }\end{array}$ \\
\hline
\end{tabular}

Fonte: Elaboração dos autores.

\section{Opção metodológica}

A opção metodológica de uma pesquisa é definida, principalmente, pelos objetivos a serem atingidos e pela orientação teórica adotada. A pergunta diretriz desta pesquisa - Quais as possibilidades de um trabalho colaborativo na formação inicial de professores que ensinam frações? - nos garante a direção da abordagem a ser adotada e nos remete diretamente a identificar, analisar e entender como os licenciandos do Curso de Pedagogia "pensam" as frações e como o trabalho colaborativo pode influenciar no processo de (re)significação dos conceitos abordados. Portanto, consideramos como adequada a abordagem qualitativa desenvolvida sobre um trabalho colaborativo, com a triangulação dos dados para efeitos de análise.

O trabalho de coleta e produção de dados foi realizado através de um curso de extensão gratuito, denominado de "Conversas sobre Frações em um Grupo Colaborativo", oferecido aos alunos de um Curso de Pedagogia de uma instituição de ensino superior do Rio Grande do Sul, com o objetivo de propiciar aos participantes a vivência em um grupo colaborativo como uma forma de viabilizar o exercício reflexivo e o processo de ressignificação do conceito de fração, bem como estimular a 
produção de estratégias e recursos para o seu ensino. Ainda, como um objetivo específico, queríamos identificar as diferentes concepções de frações que os alunos apresentavam e pensar sobre o ensino de frações através do estudo e do diálogo reflexivo no grupo colaborativo.

O referido curso contabilizou um total de 40 horas, sendo 24 horas presenciais e 16 horas referentes às tarefas realizadas, além dos oito encontros semanais realizados nas dependências da instituição de ensino, sendo as mesmas postadas no ambiente virtual, Moodle, do curso. O grupo foi constituído por aderência voluntária após a apresentação do projeto de trabalho pela coordenação do Curso de Pedagogia aos alunos. Participaram do curso oito alunos, sendo um do segundo semestre, dois formandos e os outros estavam cursando o $5^{\circ}$ ou o $6^{\circ}$ semestres. Como material de apoio foram utilizados vídeos, artigos, capítulos de livros, livros didáticos e paradidáticos e o Frac-soma $235^{1}$. Todos os encontros foram filmados para uso exclusivo da pesquisa. Quanto ao ambiente virtual do curso, este tinha como objetivo a disponibilização de um espaço para a distribuição de materiais de estudo utilizados nos encontros, postagem de relatos individuais dos participantes, eventuais trocas de informações do grupo e postagem da produção final.

O trabalho com o conceito de fração exigiu a organização de instrumentos que possibilitassem a obtenção de registros escritos de todos os participantes, dessa forma, quatro diferentes instrumentos que se constituíam em questões que contemplavam os cinco diferentes significados de fração foram utilizados ao longo dos encontros. Os instrumentos mesclaram questões elaboradas pela pesquisadora e questões extraídas dos trabalhos de Rodrigues (2005) e Malaspina (2007). Como fonte de dados e como "produto" da dissertação, foram elaborados pelos integrantes do grupo os "Folhas", que são um tipo de material didático que integrou um projeto desenvolvido pela Secretaria de Educação do Estado do Paraná no período de 2003 a 2010 e que decidimos propor como uma atividade do grupo em estudo.

Uma descrição breve desse projeto se faz necessária para evidenciar o motivo de sua escolha dentro de nossa proposta de trabalho. O "Projeto Folhas" (PARANÁ, 2007) baseava-se na produção e validação de textos de conteúdos didáticos das disciplinas curriculares da educação básica pelos professores que atuavam na rede de escolas do estado do Paraná. Os textos atendiam ao seguinte padrão, detalhado no Manual de Produção: Problema; Desenvolvimento teórico disciplinar; Desenvolvimento teórico interdisciplinar; Desenvolvimento contemporâneo; Propostas de atividades; e Referências, . A etapa de validação era o processo de revisão, correção, modificação e complementação do texto produzido em interação com outros professores. Depois da leitura, cada validador registrava seus comentários em parecer, argumentando, justificando e sugerindo ao professor-autor mudanças que 
considerava necessárias; discutia o parecer com o professor-autor que faria as adequações solicitadas em consenso. Assim, o professor-autor reelaborava seu texto, com base nas indicações do parecer, e inscrevia sua produção textual no Sistema Folhas no Portal Dia a Dia Educação e passava a acompanhar as outras fases do processo online.

Inspirados por esse projeto, como forma de obter um registro mais adequado desse processo, elaboramos um instrumento de validação contendo os aspectos a serem analisados. Destacamos, ainda, que as concepções epistemológicas do professor orientam alguns aspectos de sua prática e o Projeto Folhas convida o professor a rever suas concepções sobre a matemática, sobre o conhecimento matemático e sobre o seu papel no processo de ensino-aprendizagem. Na produção coletiva do texto, os professores-autores, pelo formato dele requerido e pela necessária adequação às diretrizes curriculares vigentes, estão produzindo um material de ensino com características próprias.

\section{Analisando o percurso, expondo os resultados}

O grupo de estudantes de pedagogia participantes da pesquisa apresentou uma atitude inicial de extremo receio e ansiedade em relação ao desenvolvimento do trabalho e registrou a existência de grandes dificuldades de compreensão dos significados de fração. Além disso, na primeira discussão do grupo o mesmo não percebia a existência de frações em seu cotidiano, visto alguns exemplos tímidos sobre os contextos de receitas culinárias. A ligação entre não perceber a fração no cotidiano e as dificuldades de compreensão de seus diferentes significados ficou evidente, pois não percebemos o que não entendemos.

A atividade do homem, quer considerada do ponto de vista individual quer do ponto de vista social, exige um conhecimento, tão completo quanto possível, do mundo que o rodeia. Não basta conhecer os fenômenos; importa compreender os fenômenos, determinar as razões da sua produção, descortinar as ligações de uns com os outros. (CARAÇA, 1951, p. 64).

Voltando as nossas primeiras observações do grupo, fomos capazes de detectar uma postura passiva de espera por ensinamentos e discursos vagos, ou ainda a repetição de jargões sem a devida fundamentação como por exemplo: "Eu acho que para a criança realmente aprender deve ser através do concreto" . Megid (2009) ao desenvolver um trabalho com formação de professores de anos iniciais cita Larrosa num aspecto que vem a respaldar o nosso registro: 
Os estudantes são submetidos a um verniz de jargões que não só não podem dominar com certa desenvoltura, mas também nem sequer entender. A gente sabe quatro palavras descontextualizadas, mas que cai bem dizê-las, e tudo se converte em uma imitação. A formação de professores é uma incorporação de pedaços banalizados de linguagem técnica, e o restante são pedaços [...]. (LAROSSA, 1995 apud MEGID, 2009, p. 59).

Durante a análise referente dos cinco significados de fração discutidos nesta pesquisa, pudemos perceber maior facilidade do grupo no trato com as frações envolvendo os significados de parte-todo, quociente e operador, enquanto que, ao trabalharem com a fração como uma medida ou como uma coordenada linear, os participantes apresentaram sérias dificuldades conceituais. A maior facilidade no trato com o significado de parte-todo vem ao encontro de resultados já obtidos por Teixeira (2008), Canova (2006) e Damico (2007).

Conforme Kieren (1981), o significado de parte-todo é fundamental e, em relação a sua compreensão, verificamos as maiores dificuldades quando a questão envolve a noção de área. O trabalho com a dupla contagem foi realizado satisfatoriamente nas representações retangulares e quadradas, quando a divisão em partes iguais foi facilitada pela forma da figura. No caso de círculos, por exemplo, a noção de área é mais exigida e, por isso, as dificuldades aumentam. Damico (2007) afirma que quando o caso envolve uma fração imprópria, o significado de parte-todo é insuficiente. Comprovamos essa afirmação no caso da representação utilizada na atividade de número um, do instrumento aplicado em nosso último encontro (Figura 1), onde estava sendo solicitada a análise das figuras e a representação da região pintada sob a forma de fração.

\section{Figura 1 - Atividade número 1: quarto instrumento diagnóstico sobre frações}

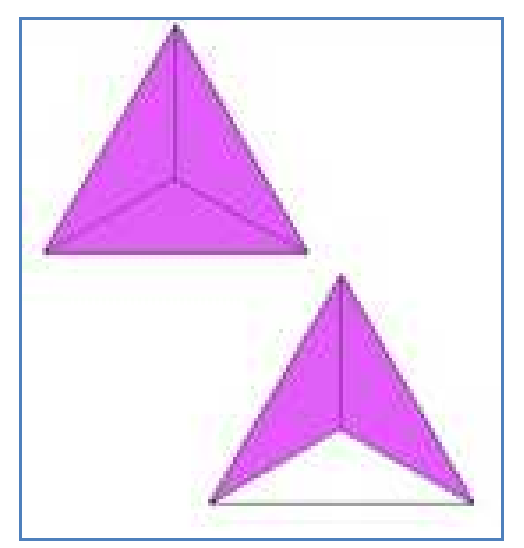

Fonte: Elaborado pelas pesquisadoras. 
Nenhum participante identificou a figura como sendo a representação de uma fração imprópria e apenas três deles fizeram o registro utilizando um número misto. A ideia da contagem das partes de um todo é mais evidente que a contagem das partes de dois todos, ou seja, 1 inteiro e 2/3 se sobrepõem à ideia de $5 / 3$.

Ainda, em relação ao significado parte-todo, no que se refere à ideia de áreas iguais, conseguimos evidenciar o progresso do grupo quanto ao seu entendimento. O desenvolvimento das atividades sobre o significado de parte-todo não pictórico e, também, com quantidades discretas não apresentaram dificuldades de resolução.

No que concerne à fração e seu significado de medida, as dificuldades do grupo foram mais expressivas. No caso da medida, embora Kieren (1980 apud DAMICO, 2007) defenda que este significado proporciona o contexto ideal para a soma de frações e para a introdução de números decimais, verificamos que dependendo da situação ele não é interpretado corretamente. Pois bem, temos que quando a comparação se restringe ao aspecto de verificarmos quantas vezes uma determinada medida cabe em outra, sendo esse número de vezes um número inteiro, não temos dificuldades significativas. Mas quando a unidade de medida é substituída por outra, sendo que esta não é múltipla ou submúltipla da anterior, a comparação exige o conceito de frações equivalentes. Menegazzi (2013) também já tinha observado essa dificuldade ao trabalhar com objetos virtuais de aprendizagem com alunos de um Curso de Pedagogia, numa experiência realizada em sala de aula.

Passando ao quinto significado de uma fração utilizado nesta pesquisa, ou seja, o de coordenada linear, na primeira atividade relacionada a esse significado já ficou nítida a dificuldade de todo o grupo em localizar corretamente as frações na reta numérica dos números racionais. Claro que sabíamos que este fato poderia vir a ocorrer, visto as pesquisas de Silva (1997), Merlini (2005) e Rodrigues (2005) já terem chegado à conclusão de que este significado é um dos que gera mais erros de interpretação. De acordo com Charalambous e Pitta-Pantazi (2007 apud LESSA, 2011), é necessário saber fazer partições da unidade, medir a partir do zero, ter noção de ordem, entre outras. Em nossas quatro atividades relativas à localização de frações na reta numérica ou na régua, não obtivemos resultados positivos. As localizações corretas foram obtidas através da utilização da divisão entre numerador e denominador, para assim obter o número decimal correspondente e, dessa forma, localizá-lo na reta numérica. Nessa interpretação, a fração não está associada a um ponto sobre a reta numérica que indica a medida de um segmento de extremidades nesse ponto e naquele que é considerado como origem. Essa concepção de fração não foi identificada. 
Através de nossas análises e apoiados em estudos focalizando o mesmo conceito, foi possível concluir que a dificuldade encontrada na fração como um número a ser representado na reta, que também está ligado ao significado de medida, é o caso que demonstrou as maiores dificuldades de compreensão, conforme afirmam Breitenbach e Búrigo (2011). Considerando que pesquisas no Brasil indicam que esse não é um significado muito explorado (CANOVA, 2006) e que a introdução da reta numérica com os números racionais não negativos pode ajudar na futura compreensão dos números irracionais (LESSA, 2011), temos aqui um sério entrave a ser superado .

$\mathrm{Na}$ continuidade do trabalho do grupo, o Frac-soma 235 foi utilizado como um recurso para a construção dos conceitos de divisão de uma medida e de equivalências e desigualdades entre frações. Durante o seu manuseio pelo grupo foi possível identificar uma carência no que se refere aos conceitos envolvendo os números naturais, como múltiplos, divisores, fatoração e mínimo múltiplo comum. Esse fato dificultava a identificação de algumas características próprias desse material. As relações entre as cores do material e sua associação com frações equivalentes não foi percebida pelo grupo. As atividades com o Frac-soma 235 evidenciaram, ainda, que os participantes ainda se encontram num estágio muito dependente de "materiais concretos", ou seja, verificou-se dificuldades no processo de abstração dos resultados obtidos através das manipulações do material. Por outro lado, ficou clara a satisfação do grupo ao trabalhar com o recurso, sendo que o mesmo foi um fator motivador de participação, auxiliando na construção de conceitos.

Contemplando as orientações contidas nos Parâmetros Curriculares Nacionais (PCN), que indicam a preocupação da inserção do estudo dos números racionais a partir de situações contextualizadas (BRASIL, 1998), partimos para a tentativa de produção de um material didático. A mobilização para a produção do "Folhas" já se constitui num movimento na formação do professor, pois ele se dispõe a estudar, pesquisar e escrever. Embora tivéssemos discutido cinco significados diferentes para as frações e também os PCN, orientando para fossem explorados em situações problema, esse aspecto não foi plenamente atingido pela produção do grupo. Verificamos certa dificuldade do grupo em formular bons problemas, que realmente refletissem uma necessidade dos alunos.

Outra exigência do "Folhas" é a sessão "Desenvolvimento Teórico", onde se espera que o professor-autor escreva sobre o conceito ao desenvolvê-lo. Criar a situação ou representá-la no ato de escrever impõe um distanciamento da situação real. Escrever sobre o conceito é diferente de falar sobre o conceito na perspectiva vigostskiana e exige habilidades específicas, como colocar as palavras numa 
sequência para constituir a frase. E isso, no caso do professor-autor do "Folhas", é sem dúvida um trabalho de formação. O desenvolvimento teórico não foi devidamente contemplado na maioria dos "Folhas" produzidos. Consideramos que os indicadores para esse fato sejam o limitado tempo do grupo no desenvolvimento do trabalho e a carência de subsídios conceituais.

O próximo quesito a ser apresentado num "Folhas" é o "desenvolvimento teórico interdisciplinar", levando em conta que o saber não pode se dar de forma fragmentada, ficando com o grupo a responsabilidade de adequar a abordagem de frações a outras áreas do conhecimento. A relação deveria ser constituída com outras duas disciplinas, o que consideramos de relativa facilidade para as alunas, visto sua formação no Curso de Pedagogia abranger fundamentos teóricos e metodológicos ligados ao ensino e a aprendizagem de todas as áreas. Mesmo assim, a relação com o objeto matemático foi, de certa forma, frágil e tímido, na medida em que as concepções do mesmo não estão bem consolidadas. Mas a evidência da pesquisa foi um exercício formativo positivo. A disciplina de ciências esteve presente em todas as produções, mostrando suas características mais próximas à matemática, e a disciplina de história aparece em três dos quatro "Folhas" produzidos, evidenciando o aspecto histórico-cultural da aprendizagem.

O “desenvolvimento contemporâneo", também presente num "Folhas", é o momento destinado à discussão dos conceitos de frações na perspectiva dos dias atuais, ou seja, sua significação no contexto dos dias de hoje. Nesse aspecto, a maior parte dos "Folhas" produzidos se propuseram a apresentar temáticas contemporâneas, como vida saudável e alimentação, índice de massa corporal e pirâmide alimentar, mas talvez a forma de apresentação ou a sequência da mesma poderia ter sido melhor distribuída.

As atividades propostas, última etapa de um "Folhas", demonstraram um significativo progresso de alguns participantes na compreensão de seu objetivo e apresentaram atividades associadas aos diferentes significados, estando eles entrelaçados ou não, sendo que apenas um deles não foi contemplado, o significado de número fracionário e sua localização na reta numérica. A observação desse fato confirma resultados de outras pesquisas que relatam que atividades voltadas a esse significado não são desenvolvidas pelos professores e muito pouco são apresentadas nos livros didáticos (CANOVA, 2006)

Reiteramos que nossos objetivos com a produção do "Folhas" eram, em primeiro lugar, obter mais uma fonte de análise para nossa pesquisa e, principalmente, provocar os participantes, desacomodá-los de uma atitude em geral percebida como passiva, acostumados a modalidades 
tradicionais de capacitação. Sempre focados em nossa questão de pesquisa, buscamos adequar a produção à perspectiva de autoformação, de criação, de protagonismo discente, exercitando conscientemente a autonomia no planejamento cuidadoso das atividades escolares. Por isso, vemos como fundamental a análise de todo o processo e não somente do produto final.

Após a análise e discussão de aspectos relacionados à fração e seus significados, abordamos evidências sobre a aprendizagem na perspectiva de um grupo colaborativo. A adesão ao grupo foi voluntária, sendo que os participantes compartilhavam de um objetivo comum, seja ele a aprendizagem de frações ou o cumprimento do total de horas relativas às atividades complementares que compõem o currículo do curso. Assim, pode ser identificado um compromisso mútuo do grupo fomentando sua constituição, ficando evidente que o grupo não se origina do fato de todos pertencerem ao mesmo curso, ou de muitos já se conhecerem, ou por qualquer outra característica desse tipo. Se assim fosse, deveríamos ter um grupo maior participando, já que a proposta de trabalho foi apresentada a vários alunos do Curso de Pedagogia. Os participantes estavam ali com o compromisso mútuo de enfrentar um trabalho diferenciado e obter um certificado.

Fiorentini (2013) afirma que o grupo se identifica não como pessoas com os mesmos conhecimentos ou do mesmo ambiente cultural, mas que possuem a mesma disposição em compartilhar o que é de interesse comum, embora possam ter olhares e entendimentos diferentes sobre os conhecimentos matemáticos, sobre a experiência de ensino e aprendizagem e outros saberes didáticopedagógicos. Desse modo, o grupo iniciou tímido e receoso quanto à forma de trabalho proposta, tomamos como exemplo para esta afirmação a fala de um dos participantes: “A gente não pensa nessa situação que a gente tá discutindo; a gente pensa que vai chegar numa oficina e lá a gente vai aprender a fazer isso, como se fosse uma receita".

Sabemos que esse é o reflexo da concepção de ensino que norteou a trajetória escolar dos participantes e que, da mesma forma, continua presente na estrutura curricular do Curso de Pedagogia e nos modelos da maioria dos projetos de oficinas de capacitação docente atuais.

As concepções de frações dos participantes se constituíram em outro ponto inicial importante para nós, pois todo nosso planejamento circundava esse objeto matemático. Assim, as lacunas verificadas na construção de conceitos relativos ao trato com números naturais foi um elemento limitador durante as discussões dos textos, na compreensão das concepções apresentadas no vídeo do primeiro encontro, no trabalho com o Frac-soma 235 e na produção do "Folhas".

Evidenciamos, também, a existência preponderante de discursos "prontos", dos clichês, das 
expressões de efeito muito empregadas no meio educacional, como, por exemplo: “A criança precisa do material concreto para aprender [...]"; "aquilo deve ter significado para a criança [...]”; "muitos professores ainda são muito tradicionais [...]"; "precisamos inserir as frações no contexto de vida da criança".

Ao afirmar que são discursos prontos queremos dizer que as falas nem sempre apresentam o necessário embasamento ou argumentação. Os participantes citaram material concreto e, quando questionados, não souberam definir o que seria "material concreto". Também os termos significado, contexto e professor tradicional estavam presentes nas falas, porém com discursos confusos, ambíguos e passíveis de diferentes interpretações. Tais discursos se encontram nas práticas da sala de aula e, mesmo com a formação universitária atual de professores, buscando uma visão mais sóciointeraconista de conhecimento e significado, ainda verificamos a força da tradição manifestada pela linguagem utilizada. Parece-nos que a compreensão consciente dos fenômenos ligados ao conhecimento e à aprendizagem fica prejudicada por crenças arraigadas, que vêm das práticas vivenciadas quando alunos.

A afiliação ao grupo, conforme Wenger (2001), comporta três modos diferentes e necessários para compreender os processos de formação de identidade e aprendizagem: compromisso, imaginação e alienação. Sendo que cada comunidade pode estar formada por diferentes combinações e proporções desses três modos. A identidade de afiliação da pesquisadora é um exemplo da combinação dos três modos, quando o compromisso se manifesta no trabalho de formar o grupo para interagir, participar e produzir, (re)construindo os significados de frações. A imaginação destaca-se quando foi necessário distanciar-se para visualizar as situações através da perspectiva dos outros, tendo de modificar a prática, ou seja, a mudança de direção e sentido dos planejamentos, de objetivos e expectativas. E, por último, a alienação no trabalho de convencer e inspirar o grupo.

Outros exemplos podem ser citados, considerando algumas análises das filmagens. Em momentos distintos vimos que alguns membros do grupo se apropriavam de relações que o restante do grupo não identificava, mas não as expunham como imposição ao grupo. Em prol do grupo, continhamse e aguardavam pelos colegas, fazendo com que o grupo seguisse o seu caminho e obtivesse as suas conclusões no momento adequado. Percebemos que alguns integrantes do grupo tinham a capacidade de entrelaçar as identidades de participação entre o compromisso, a imaginação e a alienação. Esse fato já apontava para uma futura liderança no grupo. 
Verificando as três dimensões, que unidas resultam numa comunidade de prática, podemos afirmar que todas foram identificadas no grupo de forma entrelaçada: o compromisso mútuo ao se afiliarem ao grupo, o empreendimento conjunto em manter o grupo e o que deve ser feito, ou não,, além das tarefas compartilhadas como resultado de toda a criação do grupo. Assim como, suas rotinas, expressões orais e corporais, registros que compõe suas histórias.

A participação e a não participação também estiveram evidentes no grupo, constituindo diferentes identidades de participação. Tivemos alunos com identidades de participação entrante, periférica e limitada, e alguns revezamentos permanentes entre participação e não participação, o que contribuiu para a aprendizagem, conforme Wenger (2001).

Outro destaque nesse grupo foi a importância dada ao processo de coisificação. A afirmação de uma das integrantes do grupo salienta esse fato: "As atividades propostas foram muito bem elaboradas e pensadas, atraindo a nossa atenção. Os materiais utilizados foram de grande importância para o nosso aprendizado". Coisificar o conhecimento oferece algo visível e fixo para que os participantes se esforcem para alcançar uma afiliação plena, mas não garante o alcance de formas pertinentes de participação. Porém, se o processo for todo ele descontextualizado ou procedimentalizado, estaremos desenvolvendo a dependência entre a aprendizagem e a coisificação do conhecimento, o que pode gerar uma compreensão frágil e com aplicabilidade limitada. Um exemplo para isso pode ser mencionado na característica, observada no grupo, de utilização de algoritmos, memorizados durante sua formação escolar, na resolução de determinadas atividades com frações, mas sem a apropriação dos seus conceitos e significados.

Outros registros também nos reportam ao perigo do exagero da coisificação na Educação Matemática. A referência, já citada de uma participante, ao uso de material concreto, o manuseio do Frac-soma 235 ficando restrito à contagem das peças e identificação das cores, sem o estabelecimento das relações pertinentes entre equivalência de frações e as operações com frações de denominadores diferentes, tudo isso representando uma dificuldade de abstração, de estratégias mentais, de estabelecimento de relações e de produção de significados.

A produção dos "Folhas" também contemplou o conceito de coisificação de Wenger (2001) ao apresentar um instrumento que coisifica algo da prática desse grupo, de forma cristalizada, permitindo a transferência do conhecimento resultante da produção de significados para outras comunidades de prática, outros espaços físicos, outras histórias. 


\section{Considerações finais}

Nossa proposta buscou identificar uma possibilidade de trabalho paralelo à formação inicial, querendo, com isso, viabilizar outras formas de contribuir para essa etapa, que ainda não foram contempladas pelos currículos dos Cursos de Pedagogia. Além de verificar as possibilidades desse tipo de trabalho, elencamos outras questões iniciais como forma de direcionar nosso planejamento. Assim, voltando à questão de nossa pesquisa, "Quais as possibilidades de um trabalho colaborativo na formação inicial de professores que ensinam frações?", acreditamos que temos grandes possibilidades para buscar o desenvolvimento de um trabalho colaborativo como uma alternativa na formação inicial de professores que ensinam matemática.

Identificamos alguns limitadores durante o percurso: o período curto de realização do trabalho, a postura dos participantes internalizada e apropriada através do ambiente acadêmico, alguns discursos com pouca fundamentação conceitual e, principalmente, significativas dificuldades matemáticas conceituais básicas.

Em contrapartida, algumas características ou dimensões de um grupo colaborativo foram evidenciadas. Os participantes demonstraram diferentes identidades de participação, compartilharam um objetivo comum, um empreendimento mútuo e as tarefas foram compartilhadas.

A pesquisadora, como sendo também uma integrante do grupo, foi provocada a desenvolver as diferentes dimensões de sua participação. A alternância entre as posturas de participação e de nãoparticipação, citadas por Wenger (2001), também estiveram presentes. O grupo soube determinar suas prioridades, traçando, dessa forma, seu próprio caminho e construindo a sua história de participação.

Algumas negociações de significados foram feitas, pois um progresso na resolução de atividades com frações foi percebido, embora os cinco diferentes significados abordados nesta pesquisa não tenham sido, em sua totalidade, ressignificados. Enquanto os significados de parte-todo, quociente e operador de uma fração ficaram bem estabelecidos pelo grupo, a fração como uma medida e como uma coordenada linear não apresentou o mesmo processo de ressignificação.

Acreditamos que é preciso criar esse tipo de trabalho nos Cursos de Pedagogia para desenvolver atitudes investigativas e comprometidas com a autoformação dos professores que ensinam matemática.

Os futuros professores chegam aos Cursos de Pedagogia com pré-concepções sobre o ensino e a aprendizagem de matemática, construídas durante suas trajetórias escolares, sendo estas determinantes em seu processo formativo. Caso não tenham um espaço para trazê-las à tona, discuti-las, compreendê- 
las e problematizá-las, isso pode comprometer a aprendizagem de novos conceitos e até reafirmar teorias pessoais dos professores. A matemática é difícil, é para poucos; o ensino tradicional como responsável pelo fracasso escolar e a defesa do uso de material concreto como solução para o sucesso no processo de ensino-aprendizagem são alguns exemplos de teorias pessoais identificadas em nossa pesquisa. A desmistificação e a ressignificação dessas teorias se fazem necessárias durante a formação profissional e pessoal.

É preciso repensar a Matemática e enfrentar os mitos estabelecidos. [...] A forma como os professores vêm trabalhando a Matemática ao longo dos anos pode ou não se perpetuar na formação de nossos estudantes. A quebra do mito e a revisão de práticas dependem também dos estudos e análises realizados na Graduação, nos estágios e na participação em grupos colaborativos. (NASCIMENTO, 2012, p. 48).

As limitações verificadas no desenvolvimento de nossa pesquisa não se constituem em restrições à formação de grupos colaborativos na formação inicial de professores que ensinam matemática. Acreditamos que as evidências aqui apresentadas são suficientes para afirmar que esse tipo de trabalho é importante e que deva ser entendido e discutido nos Cursos de Pedagogia.

\section{Notas}

${ }^{1}$ O Frac-soma 235 foi desenvolvido por Roberto Ribeiro Baldino e consiste em barras de mesmo tamanho $(60 \mathrm{~cm})$, que são divididas em peças congruentes com divisores de múltiplos de 2,3 e 5 . O material possui um total de 235 peças distribuídas em diferentes cores que possuem relação com os fatores dos múltiplos utilizados.

${ }^{2}$ Disponível em: <http://www.diaadiaeducacao.pr.gov.br/portals/folhas/frm_buscaFolhas.php>.

\section{REFERÊNCIAS}

BRASIL. Secretaria de Educação Fundamental. Parâmetros Curriculares Nacionais: Matemática. Brasília, DF: MEC/SEF, 1998.

BREITENBACH, Helena M.; BÚRIGO, Elisabete Z. Ensino de frações com ênfase nas concepções parte/todo, quociente e medida. In: GARCIA, Vera Clotilde V. et al. (Org.). Reflexão e pesquisa na formação de professores de matemática. Porto Alegre: Evangraf, 2011. p. 53-80.

CANOVA, Raquel Factori. Crença, concepção e competência dos professores do $1^{o}$ e $2^{o}$ ciclos do ensino fundamental com relação à fração. 2006. 220f. Dissertação (Mestrado em Educação Matemática) - Pontifícia Universidade Católica de São Paulo, São Paulo, 2006.

CARAÇA, Bento de Jesus. Conceitos Fundamentais da Matemática. Lisboa: Tipografia Matemática, 1951. 
DAMICO, Alecio. Uma investigação sobre a formação inicial de professores de matemática para o ensino de números racionais no Ensino fundamental. 2007. 316f. Tese (Doutorado em Educação) Pontifícia Universidade Católica de São Paulo, São Paulo, 2007.

FIORENTINI, Dario. Pesquisar práticas colaborativas ou pesquisar colaborativamente? In: BORBA, Marcelo de Carvalho; ARAÚJO, Jussara L. (Org.). Pesquisa Qualitativa em Educação Matemática. 5. ed. Belo Horizonte: Autêntica, 2013. p. 53-85.

FIORENTINI, Dario; GRANDO, Regina Célia; MISKULIN, Rosana Giaretta S. (Org.) Prática de formação e de pesquisa de professores que ensinam matemática. Campinas, SP: Mercado de Letras, 2009. (Série Educação Matemática).

FIORENTINI, Dario; NACARATO, Adair Mendes (Org.). Cultura, formação e desenvolvimento profissional de professores que ensinam matemática. São Paulo: Musa, 2005.

GATTI, Bernadete A.; NUNES, Marina Muniz R. (Org.). Formação de professores para o Ensino Fundamental: estudo de currículos das licenciaturas em pedagogia, língua portuguesa, matemática e ciências biológicas. São Paulo: FCC/DPE, 2009. (Coleção Textos FCC, v. 29).

KIEREN, Thomas E. Five faces of mathematical knowledge building. Edmonton: University of Aberta, 1981.

LESSA, Valéria Espíndola. A compreensão do conceito de número fracionário: uma sequência didática para o significado medida. 2011. 167f. Dissertação (Mestrado em Ensino de Matemática) Universidade Federal do Rio Grande do Sul, Porto Alegre, 2011.

MALASPINA, Maria Conceição O. O início do ensino de fração: uma intervenção com alunos de $2^{\mathrm{a}}$ série do ensino fundamental. 2007. 184f. Dissertação (Mestrado em Educação) -Pontifícia Universidade Católica de São Paulo, São Paulo, 2007.

MEGID, Maria Auxiliadora B. A. (Re)Construção do conceito da divisão na formação de professores das séries iniciais. In: FIORENTINI, Dario; GRANDO, Regina Célia; MISKULIN, Rosana Giaretta S. (Org.) Prática de formação e de pesquisa de professores que ensinam matemática. Campinas, SP: Mercado de Letras, 2009. (Série Educação Matemática). p. 53-76.

MENEGAZZI, Marlene. O Estudo de Frações: uma experiência no curso de Pedagogia. Revista Eletrônica de Educação Matemática, Florianópolis, SC, v. 8, n. 1, p. 248-265, 2013. Disponível em: < http://dx.doi.org/10.5007/1981-1322.2013v8n1p248>. Acesso em: 2 mar. 2013.

MENEGAZZI, Marlene. Potencialidades e limitações de um trabalho colaborativo sobre frações na formação inicial de professores que ensinam matemática. 2014. Dissertação (Mestrado em Ensino de Matemática) - Universidade Federal do Rio Grande do Sul, Porto Alegre, RS,2014.

MERLINI, Vera L. O conceito de fração em seus diferentes significados: um estudo diagnóstico com alunos da $5^{\mathrm{a}}$ e $6^{\mathrm{a}}$ séries do Ensino Fundamental. 2005. Dissertação (Mestrado em Educação Matemática) - Pontifícia Universidade Católica de São Paulo, São Paulo, 2005. 
NACARATO, Adair Mendes; PAIVA, Maria Auxiliadora V. (Org.). A formação do professor que ensina Matemática: perspectivas e pesquisas. Belo Horizonte: Autêntica, 2013.

NACARATO, Adair Mendes; PASSOS, Carmen L.; CARVALHO, Dione Lucchesi. Os graduandos em pedagogia e suas filosofias pessoais frente à matemática e seu ensino. Zetetiké, Campinas, SP, v. 12, n. 21, jan./jun. 2009.

NASCIMENTO, Júlia Cássia P. Estágio curricular supervisionado e grupos colaborativos na formação do professor para ensinar Matemática nos anos iniciais do Ensino Fundamental. In: CURI, Edda; NASCIMENTO, Júlia Cássia P. (Org.). Educação matemática: grupos colaborativos, mitos e práticas. São Paulo: Terracota, 2012. p. 33-53.

NUNES, Terezinha et al. The effect of situations on children understands of fractions. In: BRITISH SOCIETY FOR RESEARCH ON THE LEARNING OF MATHEMATICS, 2003, Oxford.

Proceedings... Oxford: BSRLM, 2003.

NUNES, Terezinha; BRYANT, Peter. Crianças fazendo matemática. Porto Alegre: Artes Médicas, 1997.

PARANÁ. Secretaria de Estado da Educação. Projeto Folhas. Curitiba: SEE, 2007. Disponível em: <http://www.uel.br/pessoal/jneto/gradua/historia/recdida/ManualFolhasJNETO.pdf>. Acesso em: 23 maio 2013.

RODRIGUES, Wilson Roberto. Números racionais: um estudo das concepções de alunos após o estudo formal. 2005. 247f. Dissertação (Mestrado em Educação) - Pontifícia Universidade Católica de São Paulo, São Paulo, 2005.

SILVA, Adegundes Maciel da. Investigando a concepção de frações de alunos nas séries finais do Ensino fundamental e do Ensino Médio. 2006. 126f. Dissertação (Mestrado em Ensino de Ciências) Universidade Federal Rural de Pernambuco, Recife, 2006.

SILVA, Maria José Ferreira. Sobre a introdução do conceito de número fracionário. 1997. 245f. Dissertação (Mestrado em Educação Matemática) - Pontifícia Universidade Católica de São Paulo, São Paulo, 1997.

SKOVSMOSE, Ole. Educação matemática crítica: a questão da democracia. 6. ed. Campinas, SP: Papirus, 2001.

TEIXEIRA, Alexis Martins. O professor, o ensino de fração e o livro didático: um estudo investigativo. 2008. 195f. Dissertação (Mestrado em Educação) - Pontifícia Universidade Católica de São Paulo, São Paulo, 2008.

VIGOTSKI, Lev S. A Formação social da mente. São Paulo: Martins Fontes, 1984.

WENGER, Etienne. Comunidades de práctica: aprendizaje, significado e identidad. Barcelona: Paidós, 2001. 


\section{Potentialities and limitations of a collaborative work on fractions with Pedagogy students}

\begin{abstract}
The paper presents a research work which aimed to identify the conceptions of fractions presented by a collaborative group constituted by students on Pedagogy. It also sought to analyze in which way participation on the group activities has contributed to the process of redefinition of such conceptions. Through a qualitative methodological approach, the triangulation of data in the light of the socialhistorical perspective of Vigotski, the critical mathematics education of Skovsmose and the communities of practice concept of Wenger, it was possible to identify significant features of a collaborative group on formation. The group's work was capable of generating some resignifications of the conceptions of fractions, enabling a different option of educational formation.
\end{abstract}

Keywords: Education Professional's Formation. Mathematics

\section{Potencialidades y limitaciones de un trabajo colaborativo sobre fracciones con estudiantes de Pedagogia}

\section{Resumen}

El presente texto trata de una investigación que tuvo como objetivo identificar las concepciones de fracciones que un grupo colaborativo constituido por estudiantes de Pedagogía, presenta. Analiza de qué modo la participación de las actividades del grupo contribuyó para el proceso de re significación de tales concepciones. Mediante un abordaje metodológico cualitativo, de triangulación de dados a partir de la teoría Histórica-Cultural de la escuela de Vigotski, de la educación matemática crítica de Skovsmose y de las comunidades de práctica de Wenger, fue posible identificar características significativas de un grupo colaborativo en formación. El trabajo grupal generó algunas resignicaciones de las concepciones de fracciones, viabilizando así, una forma diferente de opción en la formación.

Palabras claves: Formación de profesionales del Educación. Enseñanza de la matemática. Método de aprendizaje.
Marlene Menegazzi

E-mail: menegazzi61m@gmail.com

Andreia Dalcin

E-mail: deiadalcin@gmail.com
Enviado em: $24 / 7 / 2015$

Aprovado em: 8/3/2016 